\title{
PENGGUNAAN BERBAGAI PLASMA NUTFAH KELAPA SAWIT KOLEKSI PPKS RIAU TERHADAP POPULASI SERANGGA PENYERBUK KELAPA SAWIT
}

(Elaeidobius kamerunicus Faust.)

\section{The Use Of Various Oil Palm Germplasm Collection of Indonesian Oil Palm Resesarch Institute (IOPRI) Riau On Populations of Insect Pollinators (Elaeidobius Kamerunicus Faust.)}

\author{
Amnesty Situmeang*, Maryani Cyccu Tobing, Ameilia Zuliyanti Siregar, Agus Eko Prasetyo \\ Program Studi Agroekoteknologi, Fakultas Pertanian USU,Medan 20155 \\ *Coressponding author : E-mail : amnestysitumeang21@gmail.com
}

\begin{abstract}
This research was to study the use of various oil palm germplasm collection of Indonesian Oil Palm Research Institute (IOPRI) Riau on population of insect pollinators (Elaeidobius kamerunicus Faust.) in Riau Province Kalianta Gardens. The research was conducted from May until July 2016 by purposive sampling method. The results showed that E. kamerunicus total population of 9,123 head/0.5ha with E. kamerunicus male sex ratio of 3,160 head/0.5ha and females amounted to 5,963 heads/0.5ha in male flowers and a total population of 433 head/0.5ha with a ratio E. kamerunicus male genitals of 182 head/0.5ha and females of 251 head/0.5ha in the female flowers. The population of E. kamerunicus on more male flowers than the female flowers. Germplasm highest in V3 (Accession Wild Angola) on the male flowers and V1 (Elaeis guineensis) in the female flowers, while the lowest germplasm on male and female flowers are V7 (Elaeis oleifera).
\end{abstract}

Keywords: Elaeidobius kamerunicus, Environment, Germplasm, Population.

\begin{abstract}
ABSTRAK
Penelitian ini bertujuan untuk mengetahui penggunaan berbagai plasma nutfah kelapa sawit koleksi PPKS Riau terhadap populasi serangga penyerbuk kelapa sawit (Elaeidobius kamerunicus Faust.) di Kebun Kalianta Provinsi Riau. Penelitian dilakukan mulai bulan Mei sampai Juli 2016 dengan metode purposive sampling. Hasil penelitian diperoleh bahwa populasi total E. kamerunicus sebesar 9.123 ekor/0.5ha dengan nisbah kelamin E. kamerunicus jantan sebesar 3.160 ekor/0.5ha dan betina sebesar 5.963 ekor/0.5ha di bunga jantan dan populasi total sebesar 433 ekor/0.5ha dengan nisbah kelamin $E$. kamerunicus jantan sebesar 182 ekor/0.5ha dan betina sebesar 251 ekor/0.5ha di bunga betina. Populasi E. kamerunicus pada bunga jantan lebih banyak dibandingkan pada bunga betina. Plasma nutfah tertinggi terdapat pada V3 (Aksesi Liar Angola) pada bunga jantan dan V1 (Elaeis guineensis) pada bunga betina sedangkan plasma nutfah terendah baik pada bunga jantan maupun betina yaitu V7 (Elaeis oleifera).
\end{abstract}

Kata Kunci : Elaeidobius kamerunicus, Nisbah Kelamin, Plasma Nutfah, Populasi. 


\section{PENDAHULUAN}

Kelapa sawit (Elaeis guineensis) merupakan salah satu tanaman perkebunan di Indonesia yang memiliki nilai ekonomi tinggi sehingga menjadi salah satu sumber penghasil devisa non-migas di Indonesia. Tanaman tropis ini merupakan tanaman perkebunan terluas yang mencapai 11.300 .370 ha dari total luas perkebunan Indonesia. Pada tahun 2014 produktivitas perkebunan kelapa sawit di Indonesia menghasilkan 29.278.189 ton dan meningkat di tahun 2015 sebesar 31.284.306 ton minyak kelapa sawit (BPS, 2015).

Salah satu faktor yang penting yaitu penggunaan jenis plasma nutfah kelapa sawit selain berpotensi menghasilkan produksi yang tinggi juga akan mempengaruhi populasi E. kamerunicus (Purba et al., 2009). Beberapa produsen kelapa sawit telah berlomba-lomba untuk menciptakan bahan tanam yang mempunyai karakteristik produksi tinggi (Purba, 2010).

Proses penyerbukan bunga kelapa sawit adalah penyerbukan silang, karena dalam satu pohon tidak ditemukan bunga jantan dan betina yang mekar dalam waktu bersamaan. Salah satu perantara efektif dalam membantu proses penyerbukan bunga adalah serangga penyerbuk (Tandon et al., 2001).

Penyerbuk kelapa sawit dapat berupa angin, air, manusia, hewan vertebrata dan serangga. Serangga merupakan penyerbuk yang paling efektif dan efisien pada tanaman kelapa sawit. Serangga yang sering berperan sebagai penyerbuk bunga kepala sawit di dunia adalah Elaeidobius kamerunicus,

E. plagiatus, E. singularis, E. bilineattusm, Prosoestus sculplitis, P. minor, Thrips hawaiiensis, Pyroderces sp. dan beberapa dari ordo

Coleoptera,

Diptera, Hymenoptera serta Heteroptera (Simatupang, 2014).
Elaeidobius kamerunicus (Coleoptera: Curculionidae) merupakan salah satu serangga yang berperan penting dalam proses penyerbukan kelapa sawit. Pelepasan kumbang E. kamerunicus di Indonesia pada tahun 1982 secara signifikan meningkatkan produktivitas kelapa sawit dari $40 \%$ ke $60 \%$ (Buletin Entomologi, 2015).

Jumlah E. kamerunicus yang efektif untuk menyerbuki bunga betina adalah 20.000 ekor kumbang per hektar. Populasi E. kamerunicus kurang dari 700 ekor per tandan bunga betina anthesis akan menyebabkan fruit set menjadi rendah. Fruit set yang baik pada tanaman kelapa sawit adalah di atas 75\% (Susanto et al., 2007).

Pada umumnya bunga jantan dan betina mampu menghasilkan 10-40 gram atau sebandingkan dengan satu juta bulir serbuk sari maupun polen yang terdapat pada tangkai spikelet dengan warna putih kekuningan dengan diameter $1 \mathrm{~cm}$ (Verheye, 2010).

Berdasarkan hal tersebut diatas penulis tertarik melakukan penelitian untuk mempelajari pengaruh berbagai plasma nutfah kelapa sawit terhadap kehadiran serangga penyerbuk (E. kamerunicus).

\section{BAHAN DAN METODE}

Penelitian ini dilaksanakan di Kebun Kalianta Pusat Penelitian Kelapa Sawit (PPKS) Riau dimulai bulan Mei sampai dengan Juli 2016 dengan ketinggian tempat 10 $\mathrm{m}$ diatas permukaan laut dengan metode purposive sampling (sampling bertujuan) yaitu mengamati secara langsung E. kamerunicus pada bunga kelapa. Bahan yang digunakan dalam penelitian antara lain bunga kelapa sawit jantan anthesis dan bunga kelapa sawit betina receptive dengan plasma nutfah tersebut terdiri dari (DxT, Klon DxP, Aksesi Liar Angola, Klon FTC, Klon BC-1, BC-2 Deli, Elaeis oleifera, dan BC-2 Afrika) tahun tanam 2013 dengan tingkat kemekaran bunga sebesar $75 \%$. 
Pelaksanaan Penelitian dimulai dari :

\section{Penetapan Kebun yang akan disurvei}

Setiap plasma nutfah yang disurvei memiliki luas lahan masing-masing 0,5 ha (72 pohon). Total lahan yang digunakan seluas 4 ha.

\section{Jumlah Bunga Jantan dan Jumlah Bunga Betina Mekar}

Jumlah bunga jantan anthesis dan bunga betina receptive dihitung untuk setiap jenis plasma nutfah yang akan digunakan pada penelitian.

\section{Pengamatan Populasi Penyerbuk Kelapa Sawit}

\section{HASIL DAN PEMBAHASAN}

\section{Populasi dan Nisbah Kelamin}

E. kamerunicus pada Bunga Jantan Kelapa Sawit

Tabel 1. Populasi E. kamerunicus pada bunga jantan

\begin{tabular}{lllll}
\hline \multirow{2}{*}{ Varietas } & \multicolumn{2}{c}{ Populasi E. kamerunicus Jantan } & \multicolumn{2}{c}{ Populasi E. kamerunicus Betina } \\
\cline { 2 - 5 } & Total & Rata-rata & Total & Rata-rata \\
\hline V1 & 58919 & 818 & 91197 & 1267 \\
V2 & 27773 & 386 & 90762 & 1261 \\
V3 & 89559 & 1244 & 161368 & 2241 \\
V4 & 21159 & 294 & 30093 & 418 \\
V5 & 1200 & 17 & 3600 & 50 \\
V6 & 17699 & 246 & 28201 & 392 \\
V7 & 0 & 0 & 0 & 0 \\
V8 & 11198 & 156 & 24144 & 335 \\
Total & 227507 & 3160 & 429365 & 5963 \\
Rata-rata & 28438.375 & 395 & 53670.625 & 745 \\
\hline
\end{tabular}

Hasil penelitian pada bunga jantan kelapa sawit dari delapan plasma nutfah kelapa sawit koleksi PPKS Riau menunjukkan bahwa populasi total E. kamerunicus sebesar 9.123 ekor/0.5ha dengan nisbah kelamin yaitu populasi betina lebih tinggi sebesar 5.963 ekor/0.5ha dibandingkan populasi jantan sebesar 3.160 ekor/0.5ha (Tabel 1). Hal ini disebabkan pada umumnya daur hidup betina lebih lama 20-23 hari dibandingkan dengan
Penghitungan populasi kumbang per tandan bunga jantan anthesis, dengan mengambil masing-masing 3 spikelet bunga yang berada di bagian ujung tandan (atas). Spikelet tersebut dimasukkan ke dalam kantong plastik dan diberi kapas yang telah dibasahi 20 tetes etilalkohol dengan kadar $96 \%$.

Penghitungan populasi kumbang per tandan bunga betina receptive, dilakukan dengan menghitung jumlah E. kamerunicus yang tertangkap pada bunga betina.

\section{Peubah Amatan}

Menghitung populasi E. kamerunicus yang ditemukan pada bunga jantan anthesis dan bunga betina receptive kelapa sawit pada plasma nutfah yang diuji. jantan sehingga akan mempengaruhi waktu E. kamerunicus betina bereproduksi dan menghasilkan telur yang banyak pula. Sesuai dengan hasil penelitian Meliala (2008) yang menyatakan lama hidup imago betina E. kamerunicus lebih panjang (lama) adalah 55-60 hari dibanding dengan imago jantannya tercatat 33-43 hari.

Hasil penelitian menunjukkan bahwa nisbah kelamin E. kamerunicus pada bunga 
jantan yaitu $1: 2$, sebesar 3.160 ekor/0.5ha pada jantan berbanding sebesar 5.963 ekor/0.5ha pada betina. Hal ini sesuai dengan Prasetyo dan Susanto (2012) yang menyatakan bahwa perbandingan jumlah kumbang jantan dan betina di lapangan adalah $1: 2$. Hal ini disebabkan karena lama hidup kumbang betina dapat mencapai 65 hari dan kumbang jantan 46 hari sehingga membantu meningkatkan populasi.

Populasi E. kamerunicus jantan dan betina tertinggi terdapat pada plasma nutfah V3 (Aksesi Liar Angola) sedangkan populasi E. kamerunicus jantan dan betina terendah terdapat pada plasma nutfah V7 (E. oleifera). Didukung oleh hasil penelitian Simatupang (2014) menyatakan jika kelapa sawit tidak berbunga maka kumbang E. kamerunicus sebagai konsumen tingkat 1 tidak dapat memperoleh pakan sehingga populasi kumbang E. kamerunicus menurun. Penelitian ini menunjukkan bahwa perbedaan populasi $E$. kamerunicus pada plasma nutfah disebabkan oleh ketersediaan bunga yang berbeda yang merupakan sumber pakan E. kamerunicus dan sebagai tempat kopulasinya.
Tabel 2. Uji t-test E. kamerunicus pada bunga jantan

\begin{tabular}{lllll}
\hline & \multicolumn{3}{c}{ Test Value =0 } \\
\cline { 2 - 5 } Parameter & $\mathrm{t}$ & $\mathrm{df}$ & $\begin{array}{l}\text { Sig. } \\
\text { tailed) }\end{array}$ \\
\hline Plasma Nutfah & 22.133 & 127 & .000 \\
Nisbah Kelamin & 33.808 & 127 & .000 \\
Total & E. & 7.841 & 127 & .000 \\
kamerunicus & & & & \\
\hline
\end{tabular}

Hasil uji t-test pada penelitian menunjukkan bahwa nisbah kelamin $(\mathrm{t}=3.808)$ dan total E. kamerunicus $(\mathrm{t}=7.841)$ berbeda nyata pada $\mathrm{p}<0.000$ (Tabel 2).

Tabel 3. Uji signifikan E. kamerunicus pada bunga jantan

\begin{tabular}{|c|c|c|c|c|c|}
\hline Parameter & $\begin{array}{l}\text { Sum } \\
\text { of } \\
\text { Squar } \\
\text { es }\end{array}$ & $\mathrm{df}$ & $\begin{array}{l}\text { Mean } \\
\text { Square }\end{array}$ & $\mathrm{F}$ & $\begin{array}{l}\text { Sig } \\
.\end{array}$ \\
\hline Nisbah & & & & .00 & 1.0 \\
\hline Kelamin & .000 & 1 & .000 & 0 & 00 \\
\hline Total & 3228 & & & & \\
\hline$E$ & 1584 & & 461165 & 14. & .00 \\
\hline kamerunicus & $\begin{array}{l}05.00 \\
0\end{array}$ & 7 & 486.429 & 802 & 0 \\
\hline
\end{tabular}

$$
\text { Pada uji signifikan total }
$$

E. kamerunicus dengan nilai $\mathrm{F}=14.802$, pada $\mathrm{p}<0.05$ menunjukkan berbeda nyata terhadap plasma nutfah (Tabel 3).

Tabel 4. Uji korelasi E. kamerunicus pada bunga jantan

\begin{tabular}{|c|c|c|c|c|c|}
\hline Parameter & Uji Korelasi & $\begin{array}{l}\text { Plasma } \\
\text { Nutfah }\end{array}$ & $\begin{array}{c}\text { Jenis } \\
\text { Kelamin }\end{array}$ & $\begin{array}{c}\text { Waktu } \\
\text { Pengamatan }\end{array}$ & $\begin{array}{c}\text { Total } \\
\text { E. kamerunicus }\end{array}$ \\
\hline \multirow[t]{3}{*}{ Plasma Nutfah } & $\begin{array}{l}\text { Pearson } \\
\text { Correlation }\end{array}$ & 1 & .000 & .000 & $.476(* *)$ \\
\hline & Sig. (2-tailed) & & 1.000 & 1.000 & .000 \\
\hline & $\mathrm{N}$ & 128 & 128 & 128 & 128 \\
\hline \multirow[t]{3}{*}{ Jenis Kelamin } & $\begin{array}{l}\text { Pearson } \\
\text { Correlation }\end{array}$ & .000 & 1 & .000 & $.214(*)$ \\
\hline & Sig. (2-tailed) & 1.000 & . & 1.000 & .015 \\
\hline & $\mathrm{N}$ & 128 & 128 & 128 & 128 \\
\hline \multirow[t]{3}{*}{$\begin{array}{c}\text { Total } \\
\text { E. kamerunicus }\end{array}$} & $\begin{array}{l}\text { Pearson } \\
\text { Correlation }\end{array}$ & $.476(* *)$ & $.214(*)$ & .074 & 1 \\
\hline & Sig. (2-tailed) & .000 & .015 & .409 & . \\
\hline & $\mathrm{N}$ & 128 & 128 & 128 & 128 \\
\hline
\end{tabular}

Ket : ** Korelasi signifikan pada tingkat 0.01 .

* Korelasi signifikan pada tingkat 0.05 . 
Pada uji korelasi menunjukkan bahwa plasma nutfah koleksi PPKS Riau sebesar $r=$ 0.476, pada $\mathrm{p}<0.01$ dan nisbah kelamin sebesar $\mathrm{r}=0.214$, pada $\mathrm{p}<0.05$ berpengaruh nyata terhadap total E. kamerunicus (Tabel 4).

Berdasarkan hasil penelitian terhadap populasi E. kamerunicus jantan dan betina pada bunga jantan kelapa sawit diketahui bahwa keduanya bersifat saling mempengaruhi, karena E. kamerunicus jantan akan membantu E. kamerunicus betina dalam proses penyediaan pollen sebagai sumber pakan bagi E. kamerunicus yang menetap pada bunga kelapa sawit untuk melakukan penyerbukan. Hal ini sesuai dengan Listabarth (2001) yang menyatakan bahwa kumbang jantan dapat membawa pollen lebih banyak dibandingkan dengan kumbang betina, karena ukuran tubuh jantan lebih besar dan lebih banyak bulu pada sayapnya dibandingkan betina sehingga menguntungkan untuk melakukan proses penyerbukan.

\section{Populasi dan Nisbah Kelamin E. kamerunicus pada Bunga Betina Kelapa Sawit}

Tabel 5. Populasi E. kamerunicus pada bunga betina

\begin{tabular}{lllll}
\hline & \multicolumn{2}{c}{ Populasi E. kamerunicus Jantan } & \multicolumn{2}{c}{ Populasi E. kamerunicus Betina } \\
\cline { 2 - 5 } Varietas & Total & Rata-rata & Total & Rata-rata \\
\hline V1 & 2981 & 373 & 4650 & 581 \\
V2 & 2562 & 320 & 3482 & 435 \\
V3 & 2150 & 269 & 2897 & 362 \\
V4 & 2740 & 343 & 3635 & 454 \\
V5 & 1450 & 181 & 1693 & 212 \\
V6 & 247 & 31 & 351 & 44 \\
V7 & 0 & 0 & 1 & 0.125 \\
V8 & 988 & 124 & 1358 & 170 \\
Total & 13118 & 1640 & 18067 & 2258 \\
Rata-rata & 182 & 365 & 251 & 502 \\
\hline
\end{tabular}

Hasil penelitian terhadap populasi E. kamerunicus pada bunga betina kelapa sawit dari delapan plasma nutfah kelapa sawit koleksi PPKS Riau diperoleh populasi total sebesar 433 ekor/0.5ha dengan nisbah kelamin yaitu populasi jantan sebesar 182 ekor/0.5ha dan populasi betina sebesar 251 ekor/0.5ha. Populasi E. kamerunicus betina lebih tinggi dibandingkan dengan populasi jantan yang ada pada bunga betina. Hal ini sesuai dengan Kahono et al. (2012) yang menyatakan bahwa E. kamerunicus betina adalah serangga yang paling aktif mengunjungi bunga betina dibandingkan jantan, oleh sebab itu populasi
E. kamerunicus betina akan lebih tinggi pula pada bunga betina.

Plasma nutfah V1 (E. guineensis) sebesar merupakan populasi E. kamerunicus jantan dan betina tertinggi dan V7 (E. oleifera) merupakan populasi terendah Sesuai dengan Beaudoin and Ollivier (2012) yang menyatakan bahwa serangga yang melakukan penyerbukan pada E. oleifera adalah E. plagiatus dan E. subvitatus sementara E. kamerunicus tidak terlalu tertarik. Hal ini bisa saja terjadi karena perbedaan kandungan pollen dan serbuk sari yang pada umumnya sebesar 10-40 gram pada plasma nutfah yang menyebabkan perbedaan jenis serangga penyerbuk yang melakukan 
penyerbukan pada masing-masing plasma nutfah tersebut.

Hasil uji t-test pada penelitian menunjukkan bahwa nisbah kelamin $(\mathrm{t}=33.808)$ dan total E. kamerunicus $(\mathrm{t}=9.700)$ berbeda nyata pada $\mathrm{p}<0.000$ (Tabel 6).

Tabel 6. Uji t-test E. kamerunicus pada bunga betina

\begin{tabular}{llll}
\hline \multirow{2}{*}{ Parameter } & \multicolumn{3}{c}{ Test Value $=0$} \\
\cline { 2 - 4 } & $\mathrm{t}$ & $\mathrm{df}$ & $\begin{array}{l}\text { Sig. } \\
\text { tailed) }\end{array}$ \\
\hline $\begin{array}{l}\text { Plasma Nutfah } \\
\text { Nisbah }\end{array}$ & 22.133 & 127 & .000 \\
$\begin{array}{l}\text { Kelamin } \\
\text { Total } \\
\text { E. kamerunicus }\end{array}$ & 33.808 & 127 & .000 \\
\hline
\end{tabular}

Hasil uji signifikan total E. kamerunicus dengan nilai $\mathrm{F}=8.604$ pada $\mathrm{p}<0.05$ menunjukkan berbeda nyata terhadap plasma nutfah (Tabel 7).

\begin{tabular}{llllll}
\hline & $\begin{array}{l}\text { Sum of } \\
\text { Parameter }\end{array}$ & $\begin{array}{l}\text { d } \\
\text { Squares }\end{array}$ & $\begin{array}{l}\text { Mean } \\
\text { Square }\end{array}$ & F & Sig \\
\hline Nisbah & .000 & 7 & .000 & .00 & 1.0 \\
Kelamin & & & & 0 & 00 \\
Total & 343171 & 7 & 49024 & 8.6 & .00 \\
E. kameruicus & 1.117 & & 4.445 & 04 & 0 \\
\hline
\end{tabular}

Pada uji korelasi menunjukkan bahwa plasma nutfah koleksi PPKS Riau sebesar $r=$ 0.503 pada $\mathrm{p}<0.01$ berpengaruh nyata terhadap total E. kamerunicus (Tabel 8).

Berdasarkan hasil penelitian diketahui bahwa populasi E. kamerunicus jantan berpengaruh sangat nyata terhadap populasi betina. Hal ini menunjukkan apabila populasi E. kamerunicus jantan tinggi maka populasi betina akan tinggi pula, karena perilaku E. kamerunicus ini akan mencari pasangannya untuk melakukan kopulasi. Seperti yang dinyatakan oleh Simatupang (2014) bahwa saat E. kamerunicus dewasa, ia akan memakan tangkai sari bunga jantan yang sudah mekar dan kemudian akan mencari lawan jenisnya untuk melakukan kopulasi yang terjadi pada siang hari, antara 2-3 hari sesudah kumbang berkembang menjadi dewasa.

Tabel 7. Uji signifikan E. kamerunicus pada bunga betina

Tabel 8. Uji korelasi E. kamerunicus pada bunga betina

\begin{tabular}{|c|c|c|c|c|c|}
\hline Parameter & Uji korelasi & $\begin{array}{l}\text { Plasma } \\
\text { Nutfah }\end{array}$ & $\begin{array}{c}\text { Nisbah } \\
\text { Kelamin }\end{array}$ & $\begin{array}{c}\text { Waktu } \\
\text { Pengamatan }\end{array}$ & $\begin{array}{c}\text { Total } \\
\text { E. kameruicus } \\
\end{array}$ \\
\hline \multirow[t]{3}{*}{ Plasma Nutfah } & $\begin{array}{l}\text { Pearson } \\
\text { Correlation }\end{array}$ & 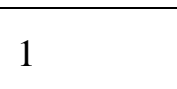 & .000 & .000 & $.503(* *)$ \\
\hline & Sig. (2-tailed) & . & 1.000 & 1.000 & .000 \\
\hline & $\mathrm{N}$ & 128 & 128 & 128 & 128 \\
\hline \multirow[t]{3}{*}{ Nisbah Kelamin } & $\begin{array}{l}\text { Pearson } \\
\text { Correlation }\end{array}$ & .000 & 1 & .000 & .136 \\
\hline & Sig. (2-tailed) & 1.000 & . & 1.000 & .126 \\
\hline & $\mathrm{N}$ & 128 & 128 & 128 & 128 \\
\hline \multirow[t]{3}{*}{$\begin{array}{l}\text { Total } \\
\text { E. kamerunicus }\end{array}$} & $\begin{array}{l}\text { Pearson } \\
\text { Correlation }\end{array}$ & $.503(* *)$ & .136 & $.372(* *)$ & 1 \\
\hline & Sig. (2-tailed) & .000 & .126 & .000 & . \\
\hline & $\mathrm{N}$ & 128 & 128 & 128 & 128 \\
\hline
\end{tabular}

Ket : ** Korelasi Signifikan pada tingkat 0.01 . 
Populasi E. kamerunicus pada bunga jantan lebih banyak dibandingkan pada bunga betina yaitu sebesar 656.782 ekor (rata-rata 9.123 ekor/0.5ha) dan sebesar 31.185 ekor (rata-rata 433 ekor/0.5ha). Hal ini terjadi karena E. kamerunicus lebih banyak berkunjung untuk mencari sumber pakan dan berkopulasi pada bunga jantan dibandingkan pada bunga betina sebab kandungan senyawa volatil yang ada pada bunga jantan lebih tinggi dibandingkan pada bunga betina. Sesuai dengan Prasetyo dan Susanto (2012) yang menyatakan bahwa senyawa volatil yang berfungsi untuk menarik serangga untuk berkunjung dan melakukan penyerbukan pada bunga kelapa sawit lebih banyak dikeluarkan oleh bunga jantan dibandingkan bunga betina kelapa sawit.

\section{SIMPULAN}

Populasi total E. kamerunicus sebesar 9.123 ekor/0.5ha dengan nisbah kelamin yaitu populasi betina lebih tinggi sebesar 5.963 ekor/0.5ha dibandingkan populasi jantan sebesar 3.160 ekor/0.5ha pada bunga jantan.

Populasi total sebesar 433 ekor/0.5ha dengan nisbah kelamin yaitu populasi jantan sebesar 182 ekor/0.5ha dan populasi betina sebesar 251 ekor/0.5ha pada bunga betina.

Plasma nutfah tertinggi terdapat pada plasma nutfah V3 (Aksesi Liar Angola) pada bunga jantan dan V1 (Elaeis guineensis) pada bunga betina sedangkan plasma nutfah terendah baik pada bunga jantan maupun betina yaitu plasma nutfah V7 (Elaeis oleifera).

\section{DAFTAR PUSTAKA}

Beaudoin L \& Ollivier. 2012. Duperie Olfactive Et Pollinisation Chez Le Palmier À Huile. Brigitte Frerot.Alassane Coffi. Albert Flori.
Badan Pusat Statistik. 2015. Statistik Perkebunan Indonesia. Direktorat Jendral Perkebunan. Jakarta.

Buletin Entomologi. 2015. E. kamerunicus. Kampus IPB Dramaga. Bogor.

Kahono S., Lupiyaningdyah P., Erniwati, \& Nugroho H. 2012. Potensi Dan Pemanfaatan Serangga Penyerbuk Untuk Meningkatkan Produksi Kelapa Sawit Di Perkebunan Kelapa Sawit Desa Api-Api, Kecamatan Waru, Kabupaten Penajam Paser Utara, Kalimantan Timur. Zoo Indonesia . 21(2):23-34.

Listabarth C. 2001. Palm Pollination by bees, beetles and flies: Why pollinator taxonomy does not matter. The Case of Hyospathe elegans (Aracaceae, Arecoidae, Areceae, Euterpeinae). Pl. Spec. Biol. 16:165-181.

Meliala. RAS. 2008. Studi Biologi Serangga Penyerbuk Kelapa Sawit Elaeidobius kamerunicus Faust. (Coleoptera: Curculionidae) Elais guineensis Jacq. di Laboratorium. Skripsi. Universitas Sumatera Utara.

Prasetyo AE., \& Susanto A. 2012. Meningkatkan Fruit Set Kelapa Sawit dengan Teknik Hatch \& Carry Elaeidobius kamerunicus. Pusat Penelitian Kelapa Sawit. Medan.

Purba AR., Supriyanto E., Supena N., \& Arif M. 2009. Peningkatan Produktivitas Kelapa Sawit dengan Menggunakan Bahan Tanam Unggul. Prosiding Pertemuan Teknis Kelapa Sawit (PTKS) Jakarta 28-30 Mei 2009. Pusat Penelitian Kelapa Sawit. Medan.

Purba RY., Harahap IY., Pangaribuan Y \& Susanto A. 2010. Menjelang 30 tahun keberadaan serangga penyerbuk kelapa sawit Elaeidobius kamerunicus Faust di Indonesia. J. Penelitian Kelapa Sawit.18(2):7385.

Simatupang, B. 2014. Pemanfaatan Serangga Penyerbuk Kelapa Sawit 
(Elaeidobius kamerunicus) Dalam Upaya Peningkatan Produktivitas Kelapa Sawit. BPP. Jambi.

Susanto A., Purba RY \& Prasetyo AE. 2007. Elaeidobius kamerunicus: Serangga Penyerbuk Kelapa Sawit. Seri Buku Saku 28. Pusat Penelitian Kelapa Sawit.

Tandon R., Manohara TN., Nijalingappa BHM., \& Shivanna KR. 2001. Pollination and pollen-pistil interaction in oil palm, Elaeis guineensis. Ann Bot. 87(1421):831838.

Verheye W. 2010. Growth and Production of Oil Palm. In: Verheye, W. (ed.), Land
Use, Land Cover and Soil Sciences. Encyclopedia of Life Support Systems (EOLSS), UNESCOEOLSS Publishers, Oxford, UK. http://www.eolss.net (diunduh tanggal 13 Februari 2016). 